\title{
Expression of Serotonin Transporter mRNA in Human Brainstem Raphe Nuclei
}

\author{
Daniel P. McLaughlin, Ph.D., Karley Y. Little, M.D., Juan F. López, M.D.,
} and Stanley J. Watson, Ph.D., M.D.

The distribution of the messenger RNA ( $m R N A$ ) encoding the serotonin transporter was investigated in the entire extent of the ascending raphe systems of the human brainstem, using a sensitive cRNA probe. This mRNA is abundant in the neurons of the raphe nuclei, especially in the dorsal and median raphe. The subregional distribution of this $m R N A$ closely corresponds to that described for tryptophan hydroxylase in immunocytochemical studies. It is expressed at the highest levels in ventral and ventro- lateral subregions of the dorsal raphe, with lower levels of expression in the median raphe, oral pontine reticular nuclei, and the supralemniscal cell groups. These results provide a description of the distribution of this $m R N A$ in normal subjects and will serve as the basis for future studies of the subregional distribution of this mRNA in the brains of depressed patients and those who have committed suicide. (c) 1996 American College of Neuropsychopharmacology [Neuropsychopharmacology 15:523-529, 1996].
KEY WORDS: Serotonin transporter; Human raphe; Gene expression; In situ hybridization

Serotonin (5-hydroxytryptamine, 5 -HT) is a neurotransmitter released from both central and peripheral neurons, where it acts on multiple subtypes of receptors (Bradley et al. 1986) to elicit a physiological response. Serotonin released from neurons also binds to a presynaptic, high-affinity, $\mathrm{Na}^{+} / \mathrm{Cl}^{-}$-dependent transporter molecule to facilitate its removal from the synaptic cleft. Human serotonin transporter cDNAs were recently cloned from placental and brainstem sources (Lesch et al. 1993; Ramamoorthy et al. 1993), facilitating studies of expression of this molecule in the human brainstem (Austin et al. 1994).

From the Mental Health Research Institute (DPM, JFL, SJW) and Ann Arbor Veterans Affairs Medical Center (KYL), Department of Psychiatry, University of Michigan Medical School, Ann Arbor, MI.

Address correspondence to: Daniel P. McLaughlin, Ph.D., Mental Health Research Institute, University of Michigan, 205 Zina Pitcher Place, Ann Arbor, MI 48109-0720.

Received January 1, 1996; revised March 13, 1995; accepted March $27,1996$.
The serotonin transporter has become one of the key molecules for study in patients suffering from affective disorder because of the several interrelated lines of evidence that point to abnormalities of serotonin transmission in this type of disease. Evidence from many sources suggests that serotonin transmission is lower in depressed patients and most markedly so in patients likely to attempt suicide (Asberg et al. 1976a, b; Roy et al. 1989). There also is some evidence that levels of the precursor molecule for serotonin synthesis tryptophan are lower in the cerebrospinal fluid (CSF) of depressed patients than in controls (Moller et al. 1983; Quintana, 1992) and that modulating dietary tryptophan can influence mood (Delgado et al. 1990). Together with the finding that the most clinically efficacious antidepressants have affinity for the serotonin transporter (for review, see Owens and Nemeroff 1994) these studies point to the importance of learning more about the regional expression of the serotonin transporter in both normal controls and depressed patients.

In the present study, we have mapped the expression of serotonin transporter mRNA in the dorsal and median raphe nuclei of human brain post mortem by the 
technique of in situ hybridization. These nuclei represent the main cell groups that send ascending serotonergic projections to the forebrain. The present study complements the work of Austin et al. (1994), who carried out an in situ hybridization analysis of serotonin transporter (5-HTt) mRNA in the human brainstem, but it is a more complete study of this system in two ways. First, we have mapped the entire extent of these nuclei, taking sections every $200 \mu \mathrm{m}$. Second, we have used a cRNA probe that, although it is highly specific, is more sensitive with the in situ hybridization technique than an oligonucleotide probe, as used by Austin et al. (1994). We compared our results to the findings in the elegant studies of brainstem serotonergic nuclei by Baker et al. (1991a, b).

\section{MATERIALS AND METHODS}

\section{Brain Material}

Human brain material was obtained from control subjects who had no history of psychiatric illness. Subjects died rapidly without receiving treatment at a hospital. This material was collected along with brains from suicide subjects and was obtained under the authorization of the chief medical examiner of the state of North Carolina. Case histories were obtained from families of the subjects in accordance with the guidelines of the Institutional Review Board (IRB) of the University of North Carolina and University of Michigan. Table 1 shows details of the subjects studied.

Brains were dissected by one of us (KYL) at autopsy into approximately $1.5-\mathrm{cm}$ thick blocks, frozen rapidly on dry ice, and stored at $-80^{\circ} \mathrm{C}$. Blocks extended rostrocaudally from the level of the trochlear nuclei to the tract of the mesencephalic trigeminal nerves. Blocks were mounted on individual chucks and $20 \mu \mathrm{m}$-thick serial sections were cut using a Lipshaw cryotome, thawmounted onto polylysine-coated microscope slides and stored at $-80^{\circ} \mathrm{C}$ until used. This yielded between 350 and 400 sections per block. Sections $200 \mu \mathrm{m}$ apart were processed for in situ hybridization to detect 5-HTt mRNA.

\section{In Situ Hybridization}

Prior to hybridization, sections were fixed in $4 \%$ paraformaldehyde (in PBS, $\mathrm{pH}$ 7.4) for 60 minutes, rinsed in 2XSSC, then partially digested with Proteinase $\mathrm{K}(0.75 \mu \mathrm{g} / \mathrm{ml}$ in $100 \mathrm{mM}$ Tris-HCl, $\mathrm{pH} 8.0,50 \mathrm{mM}$ EDTA) for 10 minutes at $37^{\circ} \mathrm{C}$. After a 1 minute wash in double-distilled water, sections were acetylated in 0.1 $\mathrm{M}$ triethanolamine $(\mathrm{pH} 8.0)$ containing $0.25 \%(\mathrm{v} / \mathrm{v})$ acetic anhydride for 10 minutes at room temperature. Sections were then washed for 5 minutes in 2XSSC, dehydrated through a graded alcohol series, air-dried, and used for hybridization.

Sections were hybridized with $1.3 \times 10^{6}$ c.p.m. of $\left[{ }^{35} \mathrm{~S}\right]$-UTP- and $\left[{ }^{35} \mathrm{~S}\right]-\mathrm{CTP}-$ labeled riboprobes in hybridization buffer at $55^{\circ} \mathrm{C}$ overnight. The hybridization buffer had the following composition: $50 \%$ formamide; 3XSSC; $50 \mathrm{mM}$ sodium phosphate (pH 7.4); $0.02 \%$ each of ficoll, polyvinylpyrrolidone, and BSA (1XDenhardt's solution); $200 \mu \mathrm{g} / \mathrm{ml}$ tRNA; and $10 \%$ dextran sulfate. Following hybridization, sections were treated with RNase A $(200 \mu \mathrm{g} / \mathrm{ml})$ at $37^{\circ} \mathrm{C}$ for 60 minutes and washed under progressively more stringent conditions, culminating in a 60 -minute wash in 0.1XSSC $(60 \mathrm{mM}$ $\mathrm{NaCl}, 6 \mathrm{mM}$ sodium citrate, $\mathrm{pH} 7.2)$ at $65^{\circ} \mathrm{C}$. Sections were then dehydrated through graded alcohols and apposed to Kodak X-OMAT film for 11 days.

Riboprobes $(1,187 \mathrm{bp})$ were synthesized using T7 (antisense) and T3 (sense) RNA polymerases, from a SacI/SmaI fragment of a human 5-HTt clone (kindly donated by Dr. R.D. Blakely, GenBank accession number L05568), subcloned into pBluescript SK. This fragment encodes a region of the 5-HTt molecule that spans the end of the putative transmembrane region 2 through the middle of the fifth extracellular loop. A series of technical controls were performed to ensure the hybridization specificity of the antisense probe used. Both sense strand and RNase-pretreated antisense-labeled sections were run in parallel with antisense-labeled sections. Under the stringent conditions used in this study, hybridization was observed only with sections labeled with the antisense probe.

In addition, to assess the general condition of mRNA in the tissues, the level of expression of mRNA encod-

Table 1. Details of Human Subjects

\begin{tabular}{lccclc}
\hline Subject \# & Age & Sex & Race & Cause of Death & $\begin{array}{c}\text { Postmortem Interval } \\
\text { (hr) }\end{array}$ \\
\hline 1 & 35 & Male & W & Cardiac & 14 \\
2 & 57 & Female & B & Bacterial sepsis & 15 \\
3 & 39 & Male & W & Cardiac & 10 \\
4 & 61 & Male & W & Motor vehicle accident & 20 \\
5 & 43 & Male & W & Cardiac & 20 \\
6 & 55 & Female & W & Cardiac & 12 \\
7 & 69 & Male & W & Gun shot wound (chest) & 22 \\
Mean \pm SE & $51.3 \pm 4.7$ & & & & $16.1 \pm 1.7$ \\
\hline
\end{tabular}


ing cyclophilin (the cyclosporin A binding protein) was evaluated in all brain samples by in situ hybridization using a probe complementary to p1B15 (Danielson et al. 1988). The level of expression of this ubiquitous and abundant mRNA served as a marker of the degree of general mRNA degradation in the brain tissues studied.

\section{Image Analysis}

In situ analysis of sections from five levels of the human raphe nuclei (characterized by Nissl staining) were compared to plates from published papers describing immunocytochemical studies of brainstem serotonergic systems (Baker et al. 1991a, b). These levels were chosen for particular features of the raphe nuclei and to allow close comparison with the findings of Baker et al. (1991a, b):

Level $1.5 \mathrm{~mm}$ above the level of the isthmus. Level of the trochlear nucleus, but ventrolateral subdivision of dorsal raphe (DR) not yet apparent. Few median raphe (MnR) cells.

Level 2. $2 \mathrm{~mm}$ above the isthmus. All the subnuclei of B7 (caudal DR) present, but few MnR cells.

Level 3. 1 to $2 \mathrm{~mm}$ caudal to the decussation of the superior cerebellar peduncles (xscp). Body of midline MnR cells now apparent. A few scattered cells in oral pontine reticular nucleus (PnO).

Level 4.6 to $7 \mathrm{~mm}$ caudal to the xscp. Many cells of the MnR close to the midline. Larger number of PnO cells, both central and dorsal. Many cells of the supralemniscal cell group (B9) are present, lying ventral to the cells of the PnO.

Level 5. 9 to $10 \mathrm{~mm}$ caudal to the xscp. MnR cells lie slightly more medially, less close to the midline-paramedian raphe. Many scattered cells in the $\mathrm{PnO}$ and more ventrally, $\mathrm{B} 9$ cells.

Autoradiograms from in situ hybridization experiments were digitized, and grey values in anatomical regions of interest were measured using quantitative densitometry. The program NIH-IMAGE, a Macintosh-based public domain program written by Wayne Rasband at the National Institutes of Health was used for this purpose. Briefly, video images of the autoradiograms were acquired and stored using an Apple Macintosh II microcomputer and a Data Translation DT2255 QuickCapture video frame grabber attached to a video camera. Grey values of regions of interest were measured using outlining tools after first using density slicing to eliminate signal below background.

Autoradiograms of three sections per subject from each of the five representative levels of the brainstem were analyzed. Consequently, data for each subject were the average of hybridization signal in the anatomical region of interest in these three sections. Measure- ments from the ventral, ventrolateral, and dorsal subdivisions of the dorsal raphe were taken from level 2 . Measurements for the MnR were taken from level 4, and the $\mathrm{PnO}$ and $\mathrm{B} 9$ cell group measures were taken from level 5. In all cases, hybridization signals (grey values) were corrected for the relative amount of cyclophilin mRNA in adjacent sections.

\section{Statistical Methods}

Grey values are expressed as mean \pm SEM. The intensity of the hybridization signal among different subregions of the raphe nuclei, but within subject, were compared by means of two-tailed paired $t$-tests, $(p<.05)$.

\section{RESULTS}

\section{5-HTt mRNA Expression}

In preliminary experiments, the level of expression of 5-HTt mRNA was measured in the dorsal raphe nucleus of the seven control subjects. However, levels of this mRNA were much lower in three subjects (numbers 2,5 , and 6). Levels of 5-HTt mRNA in these subjects were, on average, only $30 \%$ that of the others. These deficits were unrelated to such factors as age and postmortem interval (Table 1). On the basis of this finding and other experiments where cyclophilin mRNA was analyzed, these subjects were omitted from further study, as it is likely that many or most mRNAs had been degraded in these samples.

Dorsal Raphe. In the human dorsal raphe, widespread expression of the mRNA for 5-HTt was apparent (Figure 1). Perhaps the most striking aspect of the pattern of expression of this mRNA is how closely it resembles the published immunocytochemical data of Baker et al. (1991a), which describes the location and number of tryptophan hydroxylase-immunoreactive neurons in the dorsal raphe. The discrete subnuclei of this B7 cell group (dorsal, ventral, ventrolateral, interfascicular) can clearly be distinguished (Figure 1A-1C). No hybridization signal was observed in sections treated with RNase A prior to hybridization (Figure 1F).

Median Raphe. $\quad$ mRNA encoding 5-HTt was also detected in the median raphe nucleus. As with the dorsal raphe, the location of cells expressing 5-HTt mRNA closely matched that of those neurons described by Baker et al. (1991b) to be tryptophan hydroxylase-immunoreactive (Figure $1 \mathrm{C}-1 \mathrm{E}$ ). On close examination of Figure 1E, it is apparent that 5-HTt mRNA-containing MnR cells at this level are not located so close to the midline. These cells could be more accurately described as constituting the paramedian raphe nucleus. 

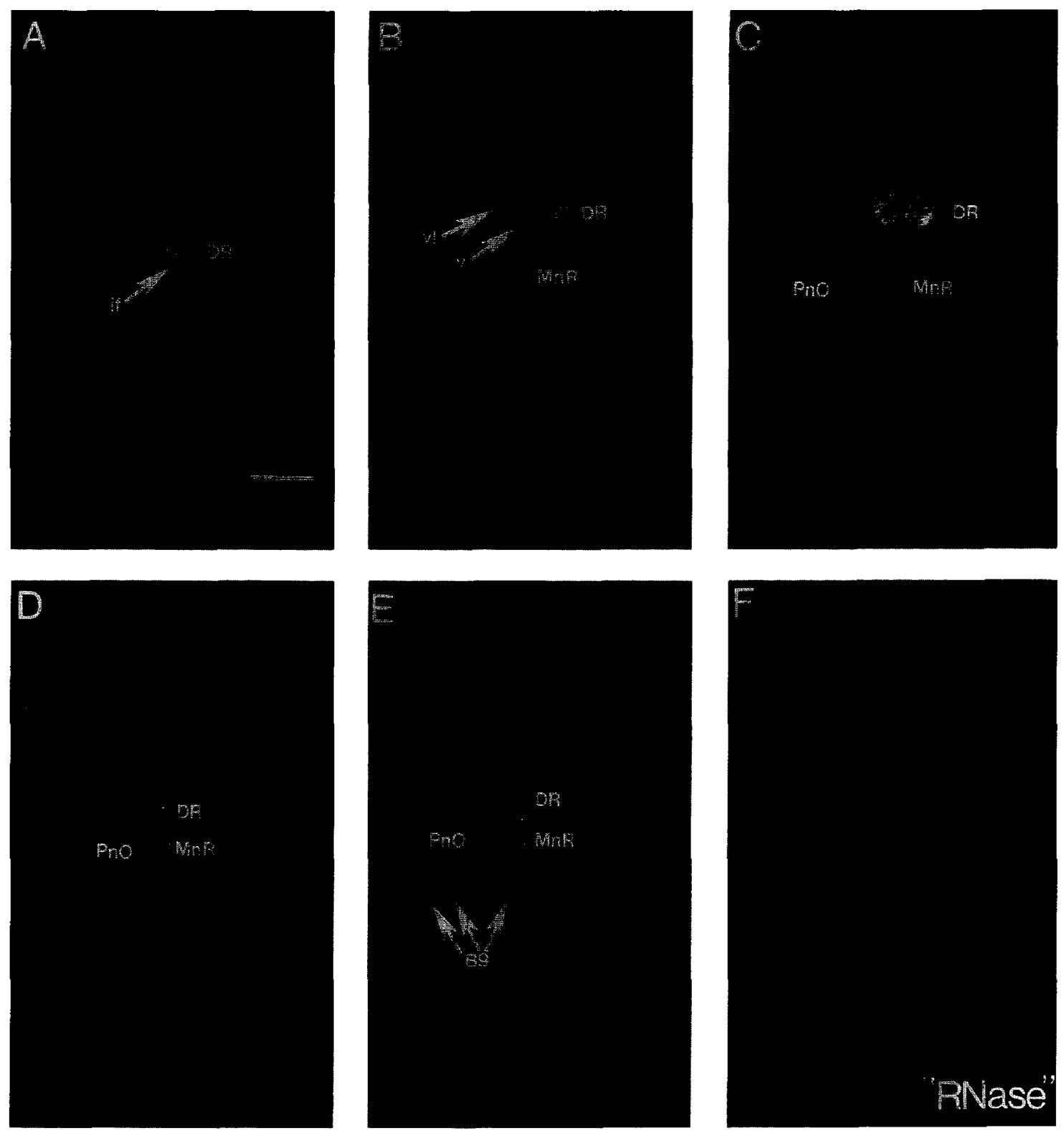

Figure 1. Dark field images of autoradiograms of 5-HT transporter mRNA detected by in situ hybridization in the human brainstem. $(A)$ Level of the trochlear nuclei (if subdivision of the DR indicated), $(B) 2 \mathrm{~mm}$ above the level of the isthmus $\left(_{\mathrm{vl}}\right.$ and $\mathrm{v}_{\mathrm{v}}$ subdivisions of DR indicated), (C) 1 to $2 \mathrm{~mm}$ caudal to $\mathrm{xscp},(D) 6$ to $7 \mathrm{~mm}$ caudal to $\mathrm{xscp},(E) 9$ to $10 \mathrm{~mm}$ caudal to xscp, $(\boldsymbol{F})$ RNase-treated section directly adjacent to that shown in $(\boldsymbol{B})$ above. If, $\mathrm{v}, \mathrm{vl}$, interfascicular, ventral, and ventrolateral subdivisions of DR; DR, dorsal raphe nucleus; MnR, median raphe nucleus; PnO, oral pontine reticular nucleus; B9, supralemniscal cell groups xscp, decussation of the superior cerebellar peduncles. Levels shown here relate to those described in the Materials and Methods section and by Baker et al. (1991a, b). Scale bar, $5 \mathrm{~mm}$.

Oral Pontine Nucleus and Supralemniscal Region. Scattered 5-HTt mRNA-positive neurons were detected in both the oral pontine nucleus and the supralemniscal region (Figure 1D-1E). The pattern of cells expressing this mRNA was again in close agreement with the description of tryptophan hydroxylase-immunoreactive neurons given by Baker et al. (1991b).

The relative amounts of 5-HTt mRNA in the different cell groups of the raphe nuclei is presented in Figure 2. The level of expression of 5-HTt mRNA is significantly higher in the ventrolateral subregion of the dorsal raphe than in the dorsal DR, MnR, PnO, or B9 cell groups $(p<.05)$.

Substantia Nigra and Locus Coeruleus. No hybridization was apparent in the dopaminergic cells of the substantia nigra or the noradrenergic neurons of the locus coeruleus. Brainstem areas that contain these cell groups are shown in Figure 1A and 1E. 


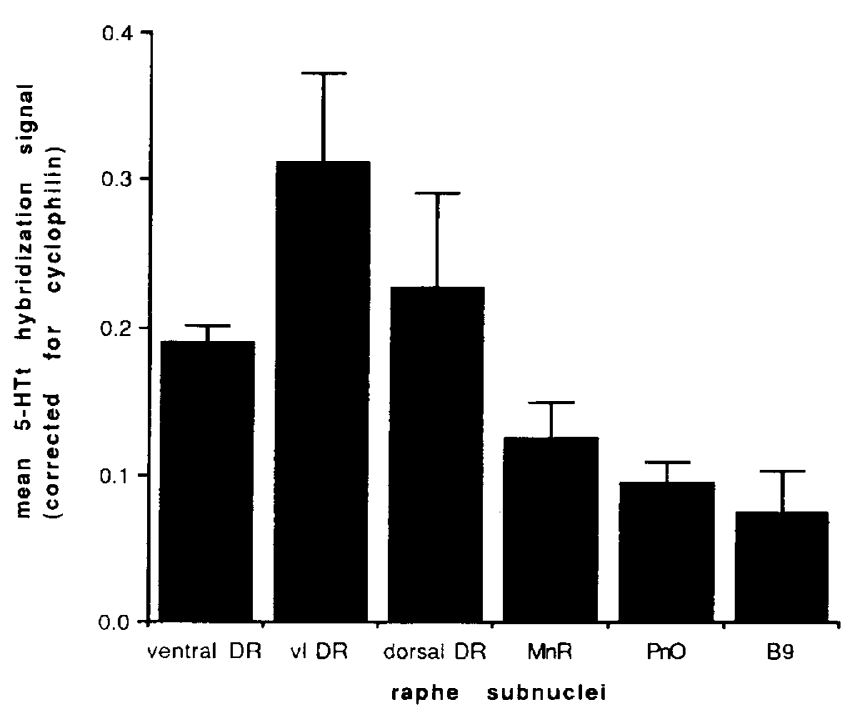

Figure 2. Relative levels of 5-HTt mRNA present in each of the subnuclei of the human raphe $(n=4)$. Data have been corrected for the level of mRNA encoding cyclophilin, a ubiquitous cellular marker, as described in the Materials and Methods section. DR, dorsal raphe; vl, ventrolateral; MnR, median raphe; PnO, oral pontine reticular nuclei; $\mathrm{B} 9$, supralemniscal cell groups.

\section{Cyclophilin mRNA Expression}

Cyclophilin mRNA (as detected by in situ hybridization with the p1B15 probe) is expressed in a ubiquitous manner in the main neuronal nuclei of the brainstem, but is expressed at particularly high levels in the pontine nuclei, consistent with findings in the rat brain (Dawson et al. 1994). On the basis of levels of this ubiquitous cellular marker, three subjects (numbers 2, 5, and 6) were omitted from the present study, as cyclophilin mRNA expression was much lower in the brainstem sections from these subjects (grey value $23.6 \pm 13.7, n=$ $3)$ than in the others $(101.9 \pm 2.6, n=4)$. We assumed that many or most of the mRNAs in the brain had been degraded because of an unknown process unrelated to age, sex, or postmortem interval. There was no correlation between these factors and the apparent mRNA degradation seen in some samples.

\section{DISCUSSION}

In this study we have mapped the expression of the mRNA for the 5-HTt in normal human brainstem in a manner that allowed us to compare the pattern of expression of this molecule to immunocytochemical studies of the serotonergic neurons of this region (Baker et al. 1991a, b). Expression of 5-HTt mRNA is correlated with the subdivisions of the raphe nuclei where tryptophan hydroxylase-immunoreactive neurons are most abundant, particularly the ventral and ventrolateral subnuclei of the dorsal raphe (Baker et al. 1991a, b). This suggests that many, if not all, of the serotonergic neurons of the human raphe nuclei express the serotonin transporter. Therefore, these nuclei may be good candidates for one of the targets of antidepressants that modulate serotonin transmission. Baker et al. (1991b) have estimated that there are significantly higher numbers of tryptophan hydroxylase-positive cells in the dorsal subnucleus of the DR $(47,000)$ than in either the ventral $(26,000)$ or ventrolateral $(30,000)$ subnuclei, but in the present study these two latter subregions appear to have disproportionately high levels of 5-HTt mRNA than would be the case if each tryptophan hydroxylasepositive neuron contained approximately the same amount of 5-HTt mRNA. However, it is not possible to make a definitive statement about the levels of mRNA per cell from autoradiographic data such as those presented here. One would have to carry out dual immunocytochemical and in situ hybridization studies of this region to address this matter fully.

The cRNA probe used in this study appears to be more sensitive than the oligonucleotide probe used by Austin et al. (1994). In comparing our Figure 1 with Figure 2 in Austin et al. (1994), it is apparent that more 5-HTt mRNA-positive cells are detected in the DR, $\mathrm{PnO}$, and $\mathrm{B} 9$ with the cRNA probe. This is probably a function of both the length and composition of the probes, and it reflects the higher avidity of long (1187 bp) cRNA-mRNA hybrids than short (48 bp) ssDNAmRNA hybrids, even under the stringent conditions used in the present study.

In the present study, with the 5-HTt probe no hybridization was seen in the substantia nigra and the locus coeruleus. Other experiments in this laboratory have shown that these regions contain dopamine transporter (DAt) and norepinephrine transporter (NEt) mRNA, respectively (data not shown). The lack of 5-HTt hybridization in these regions in the present study indicates that the degree of cross hybridization between the 5-HTt probe used here and DAt and NEt mRNAs is extremely low, despite some degree of amino acid sequence homology between the three molecules $(35-48 \%)$.

Austin et al. (1994) described three distinct mRNA species that could be detected on human raphe nuclei Northern blots and attributed this finding to alternative processing of noncoding regions of 5-HTt mRNA. The exact sequence of the cDNA probe that they used for this part of the study was not reported, but was simply described as a full-length cDNA probe. Northern blot analysis of human raphe nuclei mRNA has not been carried out in this laboratory. However, because the probe we have used for in situ hybridization is composed solely of protein-coding sequence, we suspect that this probe would detect all three mature 5-HTt mRNA transcripts in human raphe nuclei. 
One controversial matter is the question of which 5-HT receptor subtype functions as an autoreceptor in the serotonergic neurons of the human brainstem. In a recent study Burnet et al. (1995) have mapped the expression of $5-\mathrm{HT}_{1 \mathrm{~A}}$ receptor $\mathrm{mRNA}$ in human brain, including the brainstem. At a level close to that shown in Figure 1E, these authors report a very similar pattern of expression of $5-\mathrm{HT}_{1 \mathrm{~A}}$ receptor mRNA. The similarity of this pattern to that seen in a previous study for $5-\mathrm{HTt}$ mRNA (Austin et al. 1994) leads them to conclude that this receptor is likely to function as a presynaptic receptor in these neurons. Evidence from another group might support the theory that these receptors also mediate local postsynaptic contacts among neurons within this region, as $5-\mathrm{HT}_{1 \mathrm{~A}}$ receptor binding sites are abundant in the dorsal raphe (Shapiro et al. 1994). The pattern of $5-\mathrm{HT}_{1 \mathrm{~A}}$ receptor binding (by [ $\left.{ }^{3} \mathrm{H}\right]-8-\mathrm{OH}-\mathrm{DPAT}$ autoradiography) closely mirrors that for tryptophan hydroxylase-immunoreactive and 5-HTt mRNA-positive cells, especially in subnuclei of the dorsal raphe (Shapiro et al. 1994). Either these receptors are innervated by local circuits, or they are autoreceptors for serotonin released near the cell body. One can only speculate about their true physiological role without neuronal tracing and histochemical techniques. Because of both the nature of the tissue and such factors as postmortem interval, such an investigation would be difficult to carry out in human brain samples. We are presently working on a set of related studies into the expression of the mRNAs for $5-\mathrm{HT}_{1 \mathrm{~A}}$ receptors and tryptophan hydroxylase that we hope will help to clarify the role of these molecules in the modulation of serotonergic transmission in the human brainstem. We plan to investigate the question of whether the $5-\mathrm{HT}_{1 \mathrm{~A}}$ receptors in the human raphe are likely to be autoreceptors (as in rat dorsal raphe neurons) by dual in situ hybridization or in situ immunocytochemistry.

What is emerging, then, is a body of evidence that points to projection areas of the raphe nuclei as possible sites of action of antidepressant drugs that block serotonin uptake or that might work through slow desensitization of $5-\mathrm{HT}_{1 \mathrm{~A}}$ "autoreceptors" (Le Poul et al. 1995). Studies of human autopsy material such as ours remain central to the elucidation of the mechanisms of action of many psychoactive drugs, because of instances where the incorrect conclusions might be drawn from studies of laboratory animals. For example, experiments in the laboratory (Meador-Woodruff et al. 1994) have indicated that one cannot always make reliable inferences about monoamine neuronal systems from animal data. $\mathrm{D}_{2}$ dopamine receptors are present in the dopaminergic neurons of the ventral tegmental area (VTA) of the rat, where they are thought to play a role as autoreceptors, and they often have been postulated to be a possible site of action of neuroleptics because of the projections from the VTA to limbic areas. Meador-Woodruff et al.
(1994) discovered that the dopaminergic neurons of the human homologue of the VTA, the A10 cell group, were either devoid of this mRNA or contained only extremely low levels (Meador-Woodruff et al. 1994). This illustrates that care has to be applied when making comparisons between laboratory animals and man. Other important questions arise:

1. How might levels of the biosynthetic enzyme, the "autoreceptor" and transporter molecule, be affected by drug treatment?

2. Is there a relationship between the level of expression of these markers? For example, if a patient has received an antidepressant that blocks the reuptake of 5-HT, such as fluoxetine, one might expect the level of expression of 5-HTt mRNA to change.

3. Are the other molecules that determine the level of transmitter in the synapse (tryptophan hydroxylase or the autoreceptor) similarly modulated?

These important questions can be studied with the tools presently available. We hope to extend our studies of the expression of these key molecules of the serotonin system by carrying out three-dimensional reconstruction of in situ hybridization autoradiograms and statistical comparisons of expression of these mRNAs in suicide and depressed subjects.

\section{ACKNOWLEDGMENTS}

This work was supported by NIH grants PO1 MH42251 (SJW), RO1 DA09491 (KYL), K21 MH01164 (JFL) and a grant from the Scottish Rite Benevolent Foundation's Schizophrenia Research Program, Northern Masonic Jurisdiction (N.M.J.), U.S.A. (DPM). We gratefully acknowledge the help of John D. Butts, M.D., Chief Medical Examiner of the State of North Carolina, and we thank Dr. Randy D. Blakely of Emory University School of Medicine for his kind gift of human serotonin transporter cDNA.

\section{REFERENCES}

Asberg M, Traskman L, Thoren P (1976a): 5-HIAA in the cerebrospinal fluid: A biochemical suicide predictor? Arch Gen Psychiatry 33, 1193-1197

Asberg M, Thoren L, Traskman L (1976b): Serotonin depression: A biochemical subgroup within the affective disorders. Science 191, 478-480

Austin MC, Bradley CC, Mann JJ, Blakely RD (1994): Expression of serotonin transporter messenger RNA in the human brain. J Neurochem 62, 2362-2367

Baker KG, Halliday GM, Halsz P, Hornung J-P, Geffen LB, Cotton RGH, Törk I (1991a): Cytoarchitecture of serotonin-synthesizing neurones in the pontine tegmentum of the human brain. Synapse 7, 301-320

Baker KG, Halliday GM, Hornung J-P, Geffen LB, Cotton RGH, Törk I (1991b): Distribution, morphology and 
number of monoamine-synthesizing and substance P-containing neurons in the human dorsal raphe nucleus. Neuroscience 42, 747-775

Bradley PB, Engel G, Feniuk W, Fozard JR, Humphrey PP, Middlemiss DN, Mylecharane EJ, Richardson BP, Saxena PR (1986): Proposals for the classification and nomenclature of functional receptors for 5-hydroxytryptamine. Neuropharmacology 25, 563-576

Burnet PJ, Eastwood SL, Lacey K, Harrison PJ (1995): The distribution of $5-\mathrm{HT}_{1 \mathrm{~A}}$ and $5-\mathrm{HT}_{2 \mathrm{~A}}$ receptor mRNA in human brain. Brain Res 676, 157-168

Danielson PE, Forss-Petter S, Brow MA, Calavetta L, Douglass J, Milner RJ, Sutcliffe JG (1988): p1B15: A cDNA clone of the rat mRNA encoding cyclophilin. DNA 7, 261-267

Dawson TM, Steiner JP, Lyons WE, Fotuni M, Blue M, Snyder SH (1994): The immunophilins, FK506 binding protein and cyclophilin, are discretely localized in the brain: relationship to calcineurin. Neuroscience 62,569 580.

Delgado PL, Charney DS, Price LH, Aghajanian GK, Landis $\mathrm{H}$, Henninger GR (1990): Serotonin function and the mechanism of antidepressant action: Reversal of antidepressant-induced remission by rapid depletion of plasma tryptophan. Arch Gen Psychiatry 47, 411-418

Le Poul E, Laaris N, Doucet E, Laporte AM, Hamon M, Lanfumey L. (1995): Early desensitization of somato-dendritic 5- $\mathrm{HT}_{1 \mathrm{~A}}$ autoreceptors in rats treated with fluoxetine or paroxetine. Naunyn-Schmeidebergs Arch Pharmacol 352, 141-148

Lesch KP, Aulakh CS, Wolozin BL, Tolliver TJ, Hill JL, Mur- phy DL (1993): Regional brain expression of serotonin transporter mRNA and its regulation by reuptake inhibiting antidepressants. Mol Brain Res 17, 31-35

Meador-Woodruff JH, Damask SP, Watson SJ (1994): Differential expression of autoreceptors in the ascending dopamine systems of the human brain. Proc Natl Acad Sci U S A 91, 8297-8301

Moller SE, Kirk I, Brandrup E, Hollnagel M, Kaldan B, Odum K (1983): Tryptophan availability in endogenous depression: Relation to efficacy of L-tryptophan treatment. Adv Biol Psychiatry 10, 30-46

Owens MJ, Nemeroff CB (1994): Role of serotonin in the pathophysiology of depression: Focus on the serotonin transporter. Clin Chem 40, 288-295

Quintana J (1992): Platelet serotonin and plasma tryptophan decreases in endogenous depression: Clinical, therapeutic and biological correlations. J Affect Disord 24, 55-62

Ramamoorthy S, Bauman AL, Moore KR, Han H, Yang-Feng T, Chang AS, Ganapathy V, Blakely RD (1993): Antidepressant and cocaine sensitive human serotonin transporter: Molecular cloning, expression and chromosomal localization. Proc Natl Acad Sci USA 90, 2542-2546

Roy A, De Jong J, Linnoila M (1989): Cerebrospinal fluid monoamine metabolites and suicidal behavior in depressed patients. Arch Gen Psychiatry 46, 609-612

Shapiro LA, Stockmeier CA, Lowy MT, Singer JF (1994): Distribution of the serotonin $_{1 \mathrm{~A}}$ receptor, serotonin uptake site and tryptophan hydroxylase-like immunoreactivity $(\mathrm{TpH}-\mathrm{LI})$ in the human dorsal raphe. Soc Neurosci Abst 20,1547 